\title{
Plowing the Soil
}

- Plowing should be done slowly. When done slowly, the soil becomes soft, and the ox toes not tire. Spring and summer plowing should be shallow, and autumn plowing should be deep. For spring plowing, harrow the soil right after it is plowed; for autumn plowing, wait for the soil to dry out and the color turn white, then harrow.

- For dry fields, straw should be spread and burned after the first plowing. The fields will be naturally enriched after plowing again. ${ }^{1}$

- For poor fields, plow and plant mung beans. When they become lush, turn over the soil as is. Then there will be no weeds and no insects, and the barren soil will become fertile. When the soil thaws in the following year, plow once more and then sow.

- For uncultivated land, plow between seventh and eighth months and cover the land with grass. In general, when reclaiming uncultivated land, the first plowing should be deep, and the second plowing should be shallow. [If you first plow deeply and then shallowly, the subsoil is not exposed, making the soil soft and fertile.]

\footnotetext{
${ }^{1}$ The edition held by the NLK adds the following: Generally, planting mung beans is the best method for making fertile fields, and red beans and sesame are the next best method.
}

(C) The Author(s) 2019 